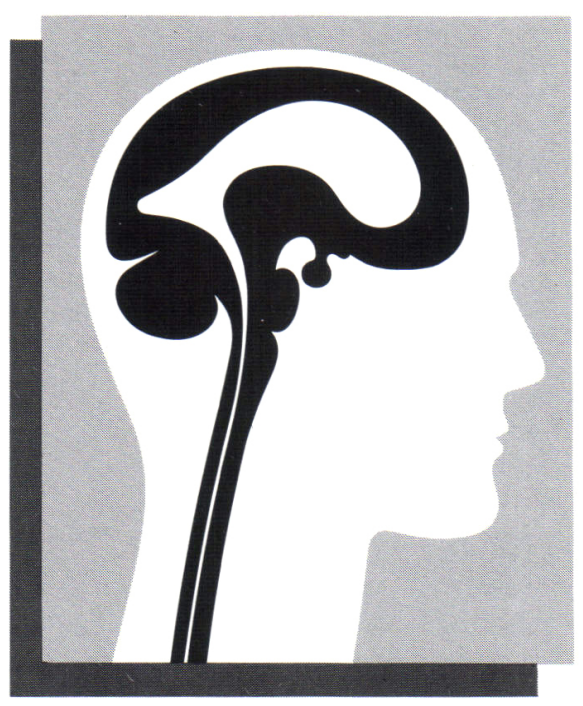

\title{
cordis Cana
}
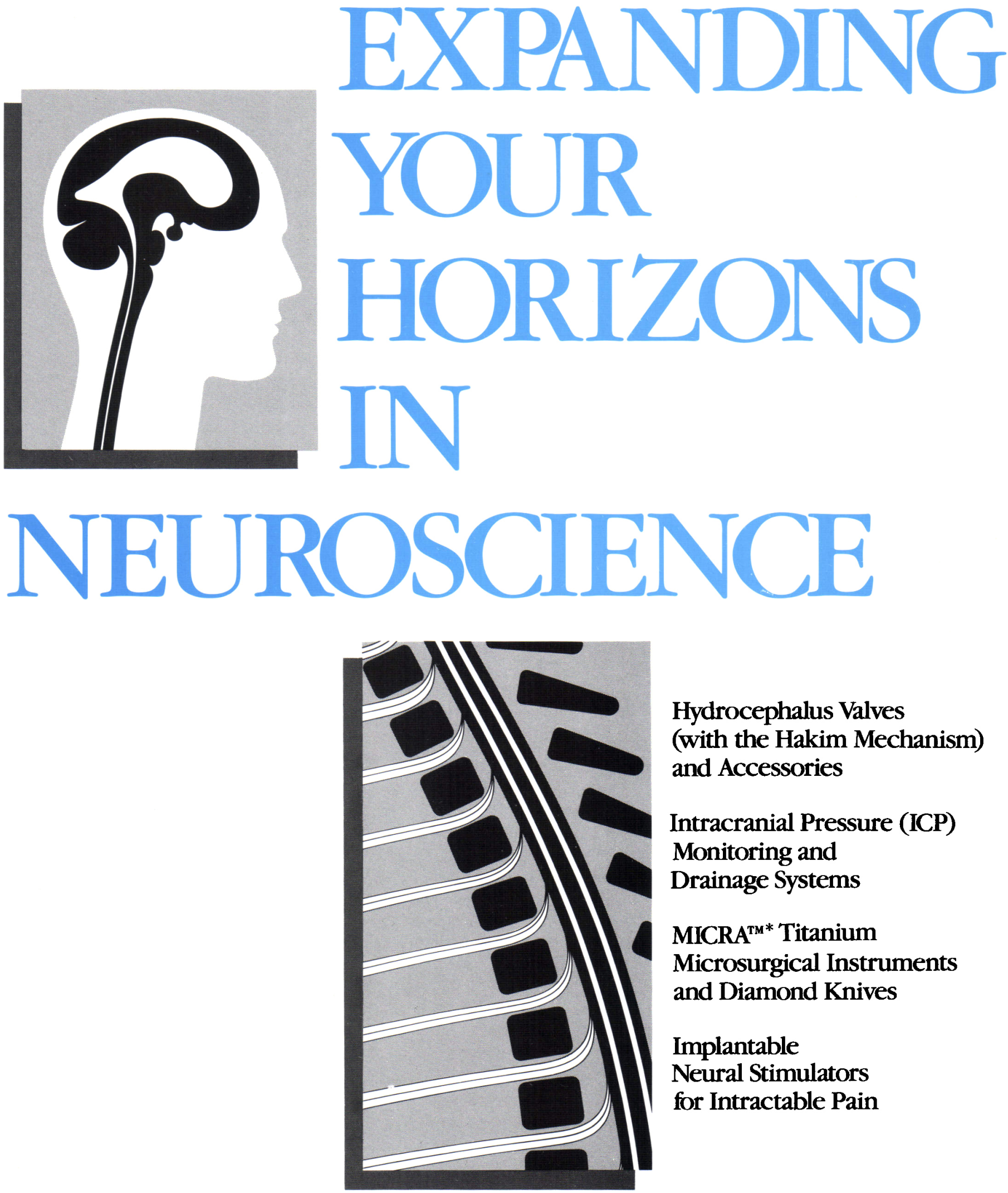

Hydrocephalus Valves (with the Hakim Mechanism) and Accessories

Intracranial Pressure (ICP) Monitoring and Drainage Systems

\section{MICRA $^{\mathrm{TM} *}$ Titanium} Microsurgical Instruments and Diamond Knives

Implantable

Neural Stimulators for Intractable Pain 


\section{Counterpoint}

$1 \mathrm{CO}_{\mathrm{m}}$.plat $v_{6} \ldots$... intrigue againss or countes ysur $n:$ a plot opposed to another coun-ter-point l'kaunt-ar-póint। $n$ I a : one or more independent melodies added above or below a given melody 2 a : a complementing or contrasting item : OPPOSIrE b : use of contrast or interplay of elements in a work of art coun.ter.poise $\backslash-$ póiz $\backslash$ vt [ME countrep

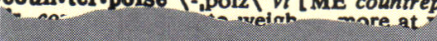

\section{The next generation} of EMG technology, today.

Counterpoint represents the start of a new era in electromyograph technology.

A system so powerful and flexible it challenges the very definition of what EMG technology can accomplish.

Imagine. One instrument that virtually does it all. And does it fast and accurately. Thanks in large part to the quality of our electrodes and amplifiers. And because at the heart of the system we've incorporated the most advanced signal processor in the industry.

Combine that power with an impressive range of software applications, and you've got a system ready to handle the most demanding jobs, from spontaneous activity and motor nerve conduction velocity to single fiber EMG and power spectrum analysis. Plus more.

And because we know how important it is for you to concentrate on your patient - we've done everything in our power to make Counterpoint as easy to use as possible. The software is userfriendly, footswitch allows you to conduct investigations - hands freeand the electrode arm can be connected to either side of the control panel for comfortable use for everyone.

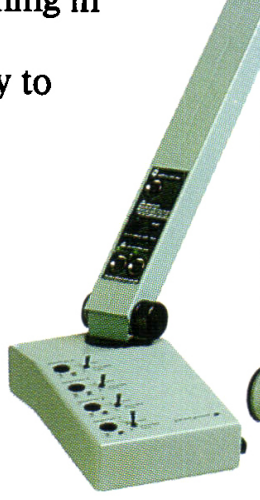

But the most surprising news is that Counterpoint is totally open to your needs. Data storage and filing can take place in an IBM Personal System $/ 2$ or AT compatible environment, so you'll never be left behind by the advent of new technologies or software developments.

Counterpoint masterfully orchestrates all the possibilities in one system. It promises to satisfy the most demanding EMG specialists in the field, and at the same time, makes your job a whole lot easier. And after all, isn't that the point?

Counterpoint from Dantec. Advanced technology in harmony with man.

Please call or write for more information.

\section{DANTEC}

Electromedical and Scientific Equipment Ltd. 140 Shorting Road Scarborough, Ontario, M1S 3S6 (416) 298-2091

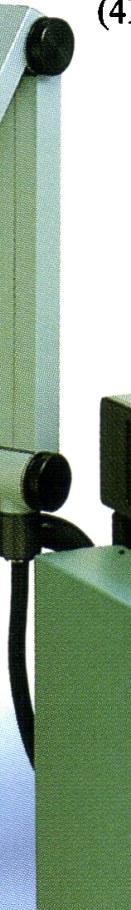




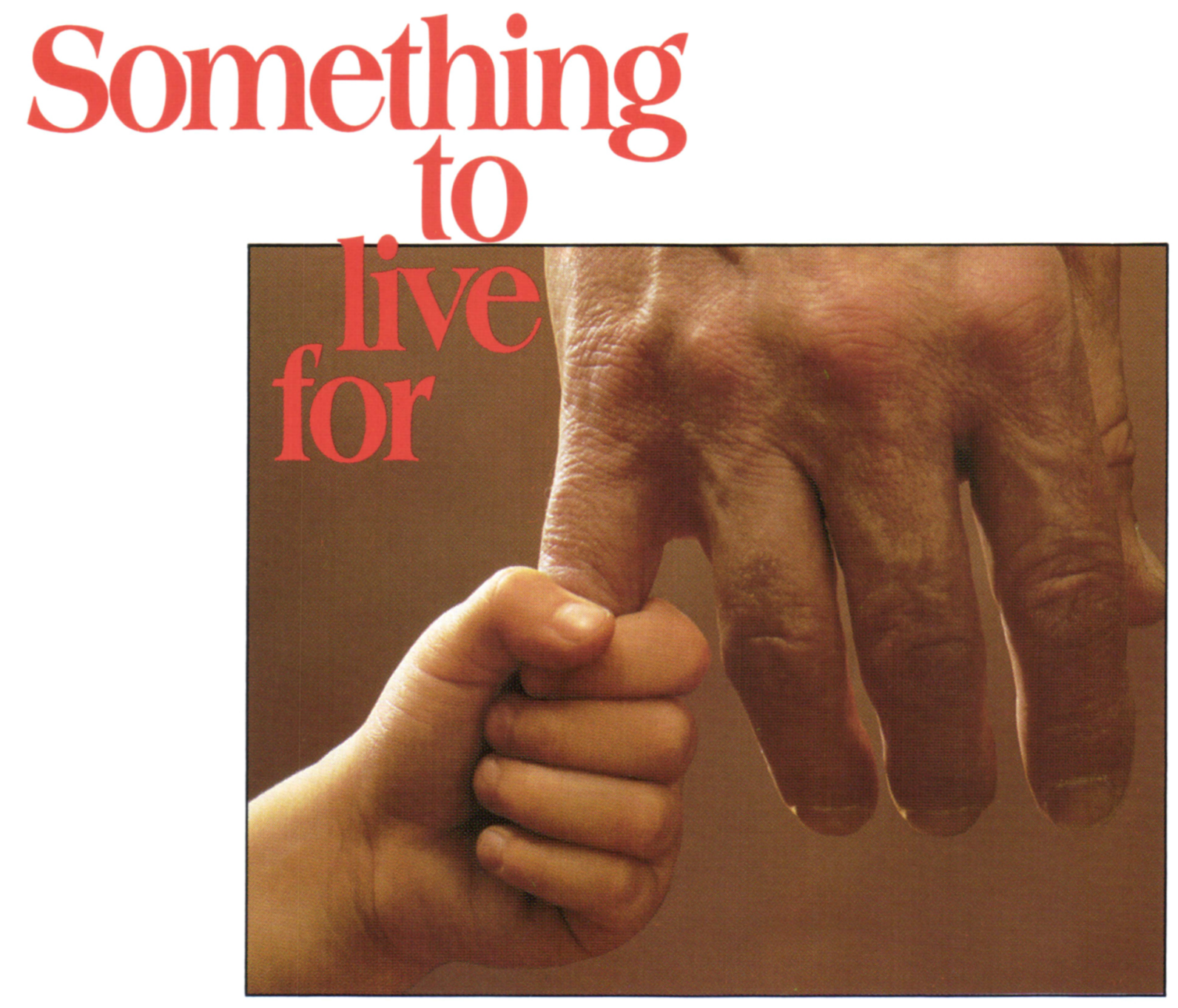

Parkinson's syndrome is an insidious assault on the lifestyles of more than 58,000 Canadians.

For these individuals, daily, routine habits like knotting a tie, or pinning the hair, are often impossible tasks.

Symmetrel ${ }^{\oplus}$ can help many of these patients gain a better hold on their daily lives, and helps you to control the syndrome.

As initial, or adjunctive therapy, Symmetrel ${ }^{\circledR}$ for Parkinson's syndrome offers:

- few significant side effects, even after long-term use.'

- noticeable benefits within 24 hours of start-up dose.'

- easy usage with levodopa and anticholinergics.'

- simple dosage regimen; simple titration.

\section{STMMIEIRE: \\ (amantadine $\mathrm{HCl}$ ) \\ can help in Parkinson's Disease}

(B)TM $\begin{aligned} & \text { PAAB } \\ & \text { CCPP }\end{aligned}$

For brief prescribing information see page xxiv 


\section{FULL PRESCRIBING INFORMATION}

\section{DILANTIN}

\section{(extended phenytoin sodlum capsules USP)}

\section{THERAPEUTIC CLASSIFICATION ANTICONVULSANT}

\section{INDICATIONS AND USAGE}

Dilantin (phenytoin sodium) is indicated for the control of generalized tonicclonic and psychomotor (grand mal and temporal lobe) seizures and prevention and treatment of seizures occurring during or followin neurosurgery. Phenytoin serum level determinations may be necessary for optimal dosage adjustments (see Dosage and Administration).

\section{CONTRAINDICATIONS}

Dilantin (phenytoin sodium) is contraindicated in those patients who are hypersensitive to phenytoin or other hydantoins.

\section{WARNINGS}

Abrupt withdrawal of Dilantin (oherytoin sodium) in epileptic patients may precipitate status epilepticus. When, in the judgement of the chinician, the need for dosage reduction, discontinuation, or substitution of alternative antiepileptic medication arises, this should be done gradually. However, in the event of an allergic or hypersensitivity reaction. rapid substitution of alternative therapy may be necessary. In this case, alternative therapy should be an antiepileptic drug not belonging to the hydantoin chemical class.

There have been a number of reports suggesting a relationship between phenytoin and the development of lymphadenopathy (local or generalized) including benign tymph node hyperplasia, pseudolymphoma, lymphoma, and Hodgkin's Disease. Although a cause and effect relationship has not been established, the occurrence of lymphadenopathy indicates the need to differentiate such a condition from other types of lymph node pathology. Lymph node involvement may occur with or without symptoms and signs resembling serum sickness, e.g. fever, rash and liver imolvement.

In all cases of lymphadenopathy, follow-up observation for an extended period is indicated and every effort should be made to achieve seizure contro using alternative antiepileptic drugs.

Acute alcoholic intake may increase phenytoin serum levels while chronic alcoholic use may decrease serum tevels.

A number of reports suggests an association between the use of antiepileptic drugs by women with epilepsy and a higher incidence of birth defects in children born to these women. Data are more extensive with respect to phenytoin and phenobarbital, but these are also the most commonly prescribed antiepileptic drugs; less systematic or anecdotal reports suggest a possible similar association with the use of all known antiepileptic drugs.

The reports suggesting a higher incidence of bitth defects in children of drug-treated epileptic women cannot be regarded as adequate to prove definite cause and effect relationship. There are intrinsic methodologic problems in obtaining adequate data on drug teratogenicity in humans: genetic lactors or the epileptic condition itself may be more important tha drug therapy in leading to birth defects. The great majority of mothers on antiepileptic medication deliver normal infants. It is important to note that antiegileptic drugs should not be discontinued in patients in whom the drug is administered to prevent major seizures, because of the strono possibility of precipitating status epilepticus with attendant hypoxia and threat to life. In individual cases where the severity and trequency of the seizure disorder are such that the removal of medication does not pose a serious threat to the patient, discontinuation of the drug may be considered prior to and during pregnancy, although it carnot be said with any confidence that even mino seizures do not pose some hazard to the developing embryo or fetus. The prescribing physician will wish to weigh these considerations in treating or counseling epileptic women of childbearing potential.

In addition to the reports of the increased incidence of congenita maltormations, such as clett lip/palate and heart malformations in children of women receiving phenytoin and other antiepileptic drugs, there have more recently been reports of a fetal hydantoin syndrome. This consists of prenata growth deficiency, microcephaly and mental deficiency in children born to mothers who have received phenytoin, barbiturates, alcohol, or trimethadions mothers who have received phenytoin, Dartiturates, alcohol, or trimethadione. intrauterine growth retardation from other causes.

There have been isolated reports of malignancies, including neuroblastoma in children whose mothers received phenytoin during pregnancy.

An increase in seizure frequency during pregnancy occurs in a high proportion of patients, because of altered phenytoin absorption or metabolism. Periodic measurement of serum phemytoin levels is particularly valuable in the management of a pregnant epileptic patient as a guide to an appropriate adjustment of dosage. However, postpartum restoration of the original dosage will probably be indicated.

Neonatal coagulation defects have been reponted within the first 24 hours in babies born to epileptic mothers receiving phenobarbital and/or phenytoin. Vitamin $K$ has been shoun to pranent or correct this defect and has been recommended to be given to the mother before delivery and to the neonate after birth.

\section{PRECAUTIONS}

Boneral

The liver is the chief site of biotransformation of Dilantin (phenytoin sodium) patients with impaired liver function, elderly patients, or those who are gravely ill may show earty signs of toxicity.

A small percentage of individuals who have been treated with phenytoin have been shown to metabolize the drug slowly. Slow metabolism may be due to limited enzyme availatility and lack of induction; it appears to be geneticalh determined.

Phenytoin should be discontinued if a skin rash appears (see 'Warnings" section regarding drug discontinuation). If the rash is exfoliative, purpuric, o bullous or if lupus erythematosus or Stevens-Johnson syndrome is suspected, use of this drug should not be resumed and alternative therapy should be considered (see Adverse Reactions). If the rash is of a milder type (measles-like or scarlatiniform), therapy may be resumed after the rash has completaly disappeared. If the rash recurs upon reinstitution of therapy, further phenytoin medication is contraindicated.
Hyperglycemia, resulting from the drug's inhibitory effects on insulin release, has been reported. Phenytoin may also raise the serum olucose level in diabetic patients.

Osteomalacia has been associated with phenytoin therapy and is considered to be due to phenytoin's interference with Vitamin D metabolism.

Pherytoin is not indicated for seizures due to hypoglycemic or other metabolic causes. Appropriate diagnostic procedures should be performed as indicated.

Phenytoin is not effective for absence (petit mal) seizures. If tonic-clonic (grand mal) and absence (petit mal) seizures are present, combined drug therapy is needed.

Serum levels of phenytoin sustained above the optimal range may produce confusional states referred to as "Velirium", "psychosis", or "encephalopatty" or rarely, ifreversible cerebellas dystunction. Accordingly, at the first sign of acuta toxicity, plasma level determinations are recommended. Dose reduction of phenytoin therapy is indicated if plasma levels are excessive; if symptoms persist, termination is recommended (seo Wernings)

Information tor Patient.

Patients taking phenytoin should be advised of the importance of adhering strictly to the prescribed dosage regimen, and of informing the physician of any clinical condition in which it is not possible to take the drug orally as prescribed, e.e. surgery, etc

Patients should also be cautioned on the use of other drugs or alcoholic beverages without first seeking the physician's advice.

Patients should be instructed to call their physician if skin rash develops. The importance of good dental tyojene should be stressed in order to minimize the development of gingival hyperplasia and its complications.

Do not use capsules which are discoloured.

\section{Inorutory Tost}

Phenytoin serum level determinations may be necessary to achieve optimal dosage adjustments.

\section{Orug Interactions}

There are many drugs which may increase or decrease phenytoin levels or which phenytoin may affect. The most commonty occurring drug interactions are listed below:

. Drugs which may increase phenytoin serum levels include: chloramphenicol, dicumarol, disulfiram, tolbutamide, isoniazid, phenylbutazone, acute alcohol intake, salicylates, chlordiazepoxide, phenothiazines, diazepam, estrogens, ethosuximide, halothane, methylphenidate, sulfonamides, cimetidine, trazodone.

2. Drugs which may decrease phenytoin levels include: carbamazepine chronic atcohol abuse, reserpine. Ingestion times of phenytoin and antacid preparations containing calcium should be staggered in patients with low serum phenytoin levels to prevent absorption problems.

3. Drugs which may either increase or decrease phentroin serum tevels include: phenobartital, valproic acid, and sodium valproate. Similarty, the effect of phenytoin on phenobarbital, valproic acio and sodium vajproate serum levels is unpredictable.

4. Although not a true drug interaction, tricyclic antidepressants may precipitate seizures in susceptible patients and phenytoin dosage may need to be adjusted.

5. Drugs whose efficacy is impaired by phentoin include: corticosteroids, coumarin anticoagulants, oral contraceptives, quinidine, vitamin $D$ digitoxin, rifampin, doxycycline, estrogens, furosemide.

Serum tevel determinations are especially helpful when possible drug interactions are suspected.

\section{Drug/Lobortory Tost Interactlons}

Phenytoin may cause decreased serum levels of protein-bound iodine (PBI). II may also produce lower than normal values for dexamethasone or metyrapone tests. Phenytoin may cause increased seurm levels of glucose, alkafine phosphatase, and gamma glutarnyl transpeptidase (GGT).

Jusing Mothow

Intant breast-feeding is not recommended for women taking this drug because phenytoin appears to be secreted in low concentrations in human milk.

Pregnancy

See WARNINGS section.

Carcinoganesls

See WARNINGS section.

\section{ADVERSE REACTIONS}

\section{Control Nerrous Sydem:}

The most common manifestations encountered with Dilantin (phenytoin sodium) therapy are referable to this system and are usually dose-related. These include nystagmus, ataxia, slurred speech, decreased coordination and mental confusion. Dizziness, insomnia, transient nervousness, motor witchings, and headaches have also been observed. There have also been rare reports of phenytoin induced dyskinesias, including chorea, dystonia, tremor and asterixis, similar to those induced by phenothiazine and other neuroleptic drugs.

A predominantly sensory peripheral polyneuropatthy has been observed in patients receiving long-term phenytoin therapy.

Gastrointoatinal Sratem:

Nausea, vomiting, and constipation.

integumentery sytom:

Dermatological manifestations sometimes accompanied by fever have included scarlatiniform or mortiliform mashes. A morbiliform rash (measles like) is the most common; other types of dermatitis are seen more rarely. Other more serious forms which may be fatal have included bullous, exfoliative or purpuric dermatitis, lupus erythematosus, and Stevens-Johnson syndrome (see Precautions).

Hemopolettc System:

Hemopoietic complications, some fatal, have occasionally been reported in association with administration of phentoin. These have included thrombocytopenia, leukopenia, oranulocytopenia, agranulocytosis, and pancytopenia with or without bone marrow suppression. While macrocytosis and megaloblastic anemia have occurred, these conditions usually respond to tolic acid therapy. Lymphadenopatty including benign lymph node yyperplasia, pseudolymphoma, Iymphoma, and Hodgkin's Disease have been reported (see Warnings).

Connective Tiasus Systom:

Coarsening of the tacial features, enlargement of the lips, gingival hyperplasia, ypertichosis and Peyronie's Disease.

Other:

Systemic lupus enthematosus, periarteritis nodosa, toxic hepatitis, liver damage, and immunoglobulin abnormalities may occur.

\section{OVERDOSAGE}

The lethal dose of Dilantin (phenytoin sodium) in children is not known. The lethal dose in adutts is estimated to be 2 to 5 grams. The initial symptoms are nystagmus, ataxia, and dysarthria. Other signs are tremor, hyperflexia, lechargy, slurred speech, nausea, vomiting. The patient may become comatose and hypotensive. Death is due to respiratory and circulatory depression.

There are marked variations among individuals with respect to phenytoin plasma levels where toxicity may occur. Nystagmus, on lateral gaze, usually appears at $20 \mathrm{mcg} / \mathrm{mL}$, ataxia at $30 \mathrm{mcg} / \mathrm{mL}$, dysarthria and lethargy apoea when the plasma concentration is over $40 \mathrm{mcg} / \mathrm{mL}$, but as high a concentration as $50 \mathrm{mcg} / \mathrm{mL}$ has been reported without evidence of toxicity. As much as $\mathbf{2 5}$ times the therapeutic dose has been taken to result in a serum concentration over $100 \mathrm{mcg} / \mathrm{mL}$ with complete recovery.

homent

Treatment is nonspecific since there is no known antidote.

The adequacy of the respiratory and circulatory systems should be caretully observed and appropriate supportive measures employed. Hemodialysis can be considered since phenytoin is not completely bound to plasma proteins. Total exchange transtusion has been used in the treatment of severe intoxication in children.

In acute ovendosage the possibility of other CNS depressants, including acohol, should be borne in mind.

\section{DOSAGE AND ADMINISTRATION}

Serum concentrations should be monitored when switching a patient from the sodium salt to the tree acid form.

Dilantin Capsules, Dilantin Parenteral, and Dilantin with Phenobarbital are formulated with the sodium salt of phenytoin. The free acid torm of phenytoin is used in Dilantin-30 Pediatric and Dilantin-125 Suspensions and Dilantin Intatabs. Because there is approximately an $8 \%$ increase in drug content with the free acid form than the sodium salt, dosage adiustments and serum level monitoring may be necessary when switching from a product formulated with the free acid to a product formulated with the sodium salt and vice versa. Genoral

Dosage should be individualized to provide maximum benefit. In some cases, serum blood level determinations may be necessary for optimal dosage adjustments - the clinically effective serum level is usually $10-20 \mathrm{mcg} / \mathrm{mL}$. Serum blood level determinations are especially helpful when possible drug interactions are suspected. With recommended dosage, a period of seven to ten days may be required to achieve therapeutic blood levels with Dilantin. Adult Dose:

Patients who have received no previous treatment may be started on one $100 \mathrm{mg}$ extended phenytoin sodium capsule three times daily, and the dose then adjusted to suit individual requirements. for most adults, the satistactory maintenance dosage will be three to tour capsules $(300-400 \mathrm{mg}$ ) daily. An increase to six capsules daily may be made, if necessary.

Pedjatrite Dose:

nitially, $5 \mathrm{mg} / \mathrm{kg} / \mathrm{day}$ in two or three equally divided doses, with subsequent dosage individualized to a maximum of $300 \mathrm{mg}$ daily. A recommended daily maintenance dosage is usually 4 to $8 \mathrm{mg} / \mathrm{kg}$. Children over 6 years old may require the minimum adult dose $(300 \mathrm{mg} / \mathrm{day})$. Pediatric dosage forms available include a $30 \mathrm{mg}$ extended phenytoin sodium capsule, a $50 \mathrm{mg}$ palatably flavoured Infatab. or an oral suspension form containing $30 \mathrm{mg}$ of Dilantin in each $5 \mathrm{~mL}$

Niternativo Dose:

Once-a-day dosage for adults with $300 \mathrm{mg}$ of extended phenytoin sodium capsules may be considered if seizure control is established with divided doses of three $100 \mathrm{mg}$ capsules daily. Studies comparing divided doses of $300 \mathrm{mg}$ with a single daily dose of this quantily indicated that absorption, peak plasma levels, biologic halt-lite, difference between peak and minimum values, and urinary recovery were equivalent. Once-a-day dosage offers a cormenience to the individual patient or to nursing personnel for institutionalized patients, and is intended only to be used for patients requiring this amount of drug daily. $A$ major problem in motivating noncompliant patients may also be lessened when the patient can take all of his medication once-a-day. However, patients should be cautioned not to inadvertenty miss a dose. Only extended phenytoin sodium capsules are recommended for once-a-day dosing.

\section{HOW SUPPUED}

DHLATIN CAPSULES: (EXTEMDED PHEHYTON SODIUM CAPSULES USP): Each white capsule with pale pink cap contains: phenytoin sodium $30 \mathrm{mg}$. Bottles of 100 and 500 .

Each white capsule with orange cap contains: pherytoin sodium $100 \mathrm{mg}$ Bottles of 100 and 1,000 .

Aleo avilable as:

Dilantin Injection:

Ready mixed 2 and $5 \mathrm{~mL}$ ampoules containing phenytoin sodium 


\section{Briet Prescribing Information}

P Tegreto ${ }^{\circledR}$ (carbamazepine)

TEGRETOL $\odot 200 \mathrm{mg}$

TEGRETOL ${ }^{\circ}$ CHEWTABS $^{\top M} 100 \mathrm{mg}$ and $200 \mathrm{mg}$

TEGRETOL ${ }^{\odot}$ CR $200 \mathrm{mg}$ and $400 \mathrm{mg}$

\section{Action}

TEGRETOL (carbamazepine) has anticonvulsant properties which have been tound usetul in the treatment of psychomotor epilepsy and, as an adjunct in the treatment of partial epilepsies, when administered in conjunction with other anticonvulsant drugs to prevent the possible generalization some patients. which seems related to the effect of the carbamazepine in psychomotor or temporal lobe epilepsy.

TEGRETOL relieves or diminishes the pain associated with trigeminal neualgia often within 24 to 48 hours.

Like other tricyclic compounds. IEGRETOL has a moderate anticholinergic action which is responsible tor some of its side effects. A tolerance may
develop to the action of TEGRETOL after a few months of treatment and develop to the action of TE

should be watched for.
TEGRETOL may suppress ventricular automaticity due to its membrane. TEGRETOL may suppress ventricular automaticity due to its membrane depressant effect similar to that of quinidine and procainamide, associated with suppression of phase 4 depolarization of the heart muscle fibre. A nurmber of investigators have reported a deterioration of EEG abnormalities with regard to focal alteratians and a higher incidence of

beta activity, during carbamazepine-combined treatment. The absorption of carbamazepine in man is relatively slow. When taken in a single oral dose, TEGRETOL (carbamazepine tablets) and TEGRETOL CHEWTABS (carbamazepine chewable tablets) yield peak plasma concentrations of unchanged carbamazepine within 4-24 hours. With respect to the quantity of carbamazepine absorbed, there is no clnically relevant difference between the vartious dosage forms. When TEGRETOL CA (carbamazepine controlled release tablets) are administered repeatedly, they yield a lower average maximal concentration of carbamazepine in the plasma, without a reduction in the average minimal concentration. This tends to result in a lower incidence of intermittent concentration.dependent adverse drug reactions. It also ensures that the plasma concentrations remain largely stable through
a twice-daily dosage.

Carbamazepine becomes bound to serum proteins to the extent of $70.80 \%$ The concentration of unchanged substance in the saliva reflects the nonprotein-bound portion present in the serum (20-30\%).

The elimination half-life of unchanged carbamazepine in the plasma averages approximately 36 hours following a single oral dose, whereas after repeated administration, which leads to autoinduction of hepatic enzymes. it averages only $16-24$ hours, depending on the duration of the medication. In patients receiving concornitant treatment with other enzyme-inducing anti-epileptic agents, half-life values averaging 9-10 hours have been found. Only 2.3\% of the dose, whether given singly or repeatedly, is excreted in the
urine in unchanged form. The primary metabolite is the pharmacologically active 10, 11-epoxide.

In man, the main urinary metabolite of carbamazepine is the trans-dio derivative orpinating from the 10, 11-epoxide' a small portion of the epoxide is converted into 9-hydroxymethyl-10-cartamoyt-acridan. Other importan biotransformation products are various monohydroxylated compounds, as well as the N-glucuronide of carbamazepine.

The therapeutic range for the steady-state plasma concentration of carba mazepine generally lies between $4.10 \mathrm{mcg} / \mathrm{ml}$.

\section{Indications and Clinical Use}

\section{A. Inigeminal Neuratg is}

TEGRETOL (carbamazepine) is indicated for the symptomatic relief of pain of trigerninal neuratgia only during periods of exacerbation of true or primary trigeminal neuralgia (tic douloureux). it should rot be used prevenlively during periods of remission. In some patients. TEGRETOL has relieved glossopharyngeal neuralgia. For patients who fail to respond to
TEGRETOL, or who are sensitive to the druo, recourse to other accepted measures must be considered.

TEGRETOL is not a simple analgesic and should not be used to relieve trivia facial pains or headaches.

\section{TEGRETOL has been found useful in:}

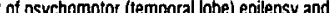

2. as an adjunct, in some patients with secondary or partial epilepsy with

complex symptomatology of secondarily generalized seizures, when

administered in combination with other antiepilieptic medication.

seizures who are experiencing marked side effects or fail to respond to other anticonvulsant drugs.

TEGRETOL is not effective in controlling petit mal, minor motor, myoclonic and predominantly unilateral seizures, and does not prevent the generalization of epileptic discharge. Moreover, recent intormation suggests that exacerba

\section{Contraindications}

TEGRETOL (carbamazepine) should not be administered to patients with history of hepatic disease or serious blood disorde.

TEGRETOL should not be administered immediately before, in conjunction with, or immediately after a monoamine oxidase inhibitor. When it seem desirable to administer TEGRETOL to a patient who has been receiving an MA0 inhibitor, there should be as long a drug-free interval as the clinica condition allows, but in no case should this be less than 14 days. Then the dosage of TEGRETOL should De low initially, and increased very gradually. TEGRETOL should not be administered to patients presenting atrioventricular heart block. (See Sections on Action and Precautions).

Sate use in pregnancy has not been established. Theretore. TEGRETOL should not be administered during the first 3 months of pregnancy. TEGRETOL should not be given to women of child-bearing potential unless, in the opinion of the physician, the expected benefits to the patient outweigh the possible risk to the fetus (See Reproductive Studies). Because of demonstrated toxicity in nursing animals TEGRETOL should not be administered to nursing mothers.

TEGRETOL should not be administered to patients with known hypersens tivity to carbamazepine of to any of the tricyclic compounds, such as amirriptyine, trimipramine, imipramine, or thei
because of the similarity in chemical structure.

\section{Warnings}

Although reported intrequently, serious adverse eftects have been observed during the use of TEGRETOL (carbamazepine). Agranulocytosis and aplastic anemia have occurred in a few instances with a fatal outcome. Leucopenia, have also been reported. It is, therefore, important that TEGRETOL should be used carefully and close clinical and trequent laboratory supervision possible signs and symptoms of a possible blood dyscrasia.

ong-term toxicity studies in rats indicated a potential carcinogenic risk (See Section on "foxicology"). Therefore, the possible risk of drug use must be weighed against the potential benefits before prescribing carbamazepine to individual patients.

\section{Precautions}

Monitoring of Kematological and Other Adverse Reactions:

Complete blood studies, including platelet counts, and evaluation of hepatic and renal function and urinalysis should be carried out before treatment is instituted. Careful clinical and laboratory supervision shoutd be maintained throughout treatment, including frequent performance of complete blood counts, in order to detect any early signs or symptoms of blood dyscrasia. Should any signs or symptoms of abnormal laboratory findings stuggestive of blood dyscrasia or liver disorder occur, TEGRETOL (Carbamazepine) Non-progressive or fluctuating asymptomatic leucopenia, which is encountered, does not generally call for the withdrawal of TEGRETOL. However, treatment with TEGRETOL should be discontinued if the patient develops leucopenia which is progressive or accompanied by clinical manifestations, e.g. fever or sore throat.

Uninary Retention and Increased Introcubr Pressure

Because of its anticholinergic action, TEGRETOL should be given cautiously. at all, to patients with iscreased intraocular pressure or urinary retention. Occurrence of Behovioural Disorders:

Occurresee of Behovioural Disonders:
Because it is closely related to the other tricyclic drugs, there is some Because it is closely related to the other tricyclic drugs, there is some
possibility that TEGRETOL might activate a latent psychosis. or, in elderly posiients, produce agitation or confusion, especially when combined with patients, produce agitation or confusion, especially when
other drugs. Caution should also be exercised in alcoholics.

Use in Patients with Cantiovascular Olsorders:

TEGRE OL should be used cautiously in patients with a history of coronary artery disease, organic heart disease, of congestive failure. if a defectiv administering TEGRETOL, in order to exclude patients with atrioventricular

\section{Driving and Operaiting Hazardous Machinery}

Because diziness and drowsiness are possible side effects of TEGRETOL. patients should be warned about the possible hazards of operating machinery or driving automobi

Orug interections:

Induction of hepatic enzymes in response to TEGRETOL may have the effect of diminishing the activity of certain drugs that are metabolized in the liver. This should be considered when administering TEGRETOL conco

Concomitant administration of TEGRETOL with verapamil, diltiazem, erythromycin, troleandomycin, cimetidine, propoxyphene or isoniazid, has been eported to result in elevated plasma levels of carbamazepine. Since an increase in the blood levels of carbamazepine may result in unwanted effects (e.g. dizziness, headache, ataxia, diplopia and nystagmus may
occur) the dosage of carbamazepine should be adapted accordingly and occur), the dosage of

The concomitant administration of carbamazepine and lithium may increas the risk of neurotoxic side eftects.

in patients receiving oral anticoagulant medication. the dosage of the anticoagulant shoutd be readapted to clinical requirements whenever trea ment with TEGRETOL is initiated or withdrawn.

TEGRETOL, like other anticonvulsants, may adversely affect the reliability o oral contraceptives. Patients should accordingly be advised to use som atternative, non-hormonal method of contraception.

TEGRETOL, like other psycho-active drugs, may reduce the patient's alcohol tolerance; it is therefore advisable to abstain from alcohol consumption during treatment.

TEGRETOL should not be administered in conjunction with an MAO inhibitor. (See Section on Contraindications).

\section{Adverse Reactions}

The reactions which have been most frequenily reported with TEGRETOL (carbamazepine) are drowsiness, unsteadiness on the feet, vertigo, dizz ness, gastrointestinal disturbances, and nausea. These reactions usually accur only during the initial chase of therapy. They have rarely necessitated ment at a low dosage.

The more serious adverse reactions observed are the hematologic, hepatic cardiovascular and dermatologic reactions. which require discontinuation of therapy. If treatment with TEGRETOL has to be withdrawn abruptly, the change-over to another anti-epileptic drug should be effected under cover of diazepam.

The following adverse reactions have been reported:

Hematologic - Transitory leucopenia, eosinophilia, hyponatremia, leucocy tosis, thrombocytopenic purpura, agranulocytosis, macrocytic anemia and aplastic anemia, In a few instances, deaths have occurred.

Hepatic - During the long-term administration of TEGRETOL, abnormalities in liver function tests,

Dermatologic - The following reactions occurred during treatment with TEGRETOL: skin sensitivity reactions and rashes, erythematous rashes, prurtic eruptions, urticaria, photosensitivity, pigmentary changes, neuronecrolysis, extoliative dermatitis, alopecia, diaphoresis, erythema multiforme, erythema nodosum, and aggravation of disseminated lupus forme, erythem

Neurologic - The reactions reperted as occurring during treatment with TEGRE mor dis

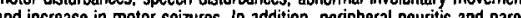
thesia. depression with agitation, talkativeness. nystagmus, hyperacusis, thesia, depression with agitation, talkativeness. nystagmus, hyperacusis,
and tinnitus have been reported but only very rafely. There have been some and tinnitus have been reported but only very rarely. There have been some
reports of paralysis and other symptoms of cerebral arterial insufficiency but no conclusive relationship to the adrninistration of TEGRETOL could be established.

Cardiovascular - Thromboembolism, recurrence of thrombophlebitis in patients with a prior history of thrombophlebitis, primary thrombophisbitis, congestive heart failure, aggravation of hypertension, Stokes.Adarns in patients with AV block, hypotension, syncope and collapse, edema, aggramyocardial infarction and arthythmia) have been associated with other tricyclic compounds.

Genitourinary - Urinary frequency, acute urinary relention, oliguria with elevated blood pressure, azotemia, renal tailure. and impotence. Elevation of BUN, albuminuria and glycosuria also have been observed.

Respiratory - Pulmonary hypersensitivity characterized by tever, dyspnea, oneumonitis or meumonia.

Gastrointestinal - Oisturbances associated with TEGRETOL therapy haye included nausea, vomiting, gastric or abdominal discomfort, diarthea or constipation, anorexia and dryness of the mouth and throat, glossitis and

Ophthalmic - There is no conclusive evidence that TEGRETOL produces pathological changes in the cornea, lens or retina. However, it should be recognized that many phenothiazines and related drugs have been shown to cause eye changes. By analogy. periodic eye examination
lamp fundoscopy and tonometry, are recommended.

Other reactions reported during treatment with TEGRETOL include fever and chills, aching joints and muscles, leg cramps, conjunctivitis, and adenopathy or lymphadenopathy.

\section{Symploms and Treatment of Overdosage}

Symptams of Ovendosage: nausea, vomiting, restlessness, agitation, disorientation; tremor, involunmydriasis, nystagmus; flushing, cyanosis, and urinary retention. Hypotenmydriasis, nystagmus; : tushing, cyanosis, and urinary retention. Hypotenmay occur. The laboratory findings in isolated instances of overdosage have included leukocytosis, reduced leukocyte count. glycosuria and acetonuria. Treatment of Overdosape:

There is no known specific antidote to TEGRETOL (carbamazepine). Experience with accidental TEGRETOL overdosage is limited. Since TEGRETOL is chemically related to the tricyclic antidepressants,
TOFRANIL (imipramine) overdosage is relevant.

It is recommended that emesis be induced, and that gastric lavage be performed. Vital signs should be watched and symptomatic treatment should be administered as required. Hyperirritability may be controlled by the administration of parenteral diazepam or barbiturates. However, barbittrates should not be used if drugs that inhibit monoamine oxidase have also
been taken by the patient, either in overdosage or in recent therapy (within been taken by th

Barbiturates may also induce respiratory depression, particularty in children. It is theretore advisable to have equipment available for artificia ventilation and resuscitation when barbiturates are employed. Paraldehyde may be used to $c$ cun
tory uepression.

Shock (circutatory collapse) should be treated with supportive measures. including intravenous fluids, oxygen, and corticosteroids.

It is recornmended that the electrocartiogram be monitored, particularly in children, to detect any cardiac armythmias or conduction defects.

\section{Dosage and Administration}

\section{Use in Eplicasy (seo indicalions):}

A low initial daily dosage of TEGRETOL (carbamazepine) with a gradual the individual patient.

TEGRETOL tablets and CHEWTABS should be taken in 2 to 4 divided doses daily, with meals whenever possible.

The controlled release characteristics of TEGRETOL CR reduce the daily fluctuations of plasma cartamazepine. TEGRETOL CR tabiets (either whole or, if so prescribed, onty half a tablet) should be swallowed unchewed with a prescribed as a twice-daily dosage. If necessary, three divided doses may be prescribed.

\section{duth and candren over 12 yars of Age:}

Chitially, 100 to $200 \mathrm{mg}$ once or twice a day depending on the severity of the case and previous therapeutic history. The initial dosage is progressively increased, in divided doses, until the best response is obtained. The usual optimal dosage is 800 to $1200 \mathrm{mg}$ daily. In rare instances some aduft been obave receved $1600 \mathrm{mg}$. As soon as disappearance of seizures has until a minimum effective dose is reached.

\section{Chilloren 6-12 vears of Age:}

Initially. $100 \mathrm{mg}$ in divided doses on the first day. Increase gradually by adding $100 \mathrm{mg}$ per day until the best response is obtained. Dosage should generally not exceed $1000 \mathrm{mg}$ daily. As soon as disappearance of seizures gradually until a minimum effective dose is reached.

\section{Use in Tripeminal Neuralgi}

The initial daity dosage should be small; $200 \mathrm{mg}$ taken in 2 doses of $100 \mathrm{mg}$ each is recommended. The total daily dosage can be increased by $200 \mathrm{mg}$ day until relief of pain is obtained. This is usually achieved at dosage between 200 and $800 \mathrm{mg}$ daily, but occasionally up to $1200 \mathrm{mg} /$ day may be progressive reduction in dosage should be attempted until a minimal effective dosage is reached. Because trigeminal neuralgia is characterized by use of TEGRETOL at intervals of not more than 3 months, depending upo the individual clinical course.

Prophylactic use of the drug in trigeminal neuralgia is not recommended. 
PLIORESAL

(baclofen)

Muscle relaxant

Antispastic agent

\section{INDICATIONS AND CLINICAL USES}

Alleviation of signs and symptoms of spasticity resulting from multiple sclerosis. Spina cord injuries and other spinal cord diseases.

\section{CONTRANOTCATIONS}

Hypersensitivity to LIORESAL.

WARNINGS

Abrupt Drug Withdrawal: Except for serious adverse reactions, the dose should be reduced slowly when the drug is discontinued to prevent visual and auditory hallucinations, confusion, anxiety with tachycardia and sweating, and worsening of spasticity.

Impaired Renal Functlon: Caution is advised in these patients and reduction in dosage may be necessary.

Stroke: Has not been of benefit and patients have shown poor tolerability to the drug.

Pregnancy and Lactation: Not recommended as safety has not been established. High doses in rats and rabbits are associated with an increase of abdominal hernias and ossification defects in the fetuses.

PRECAUTIONS

Not recommended in children under 12 as safety has not been established.

Because sedation may occur, caution patients regarding the operation of automobiles or dangerous machinery, activities made hazardous by decreased atertness, and use of alcohol and other CNS depressants.

Use with caution in spasticity that is utilized to sustain upright posture and balance in locomotion, or whenever spasticity is utilized to obtain increased function, epilepsy or history of convulsive disorders (clinical state and EEG should be monitored), peptic ulceration, severe psychiatric disorders, elderly patients with cerebrovascular disorders, and patients receiving antihypertensive therapy.

\section{ADVERSE REACTIONS}

Most common adverse reactions are transient drowsiness; dizziness, weakness and fatigue. Others reported:

Neuropsychiatric: Headache, insomnia, euphoria, excitement, depression, confusion, hallucinations, paresthesia, muscle pain, tinnitus, slurred speech, coordination disorder, tremor, rigidity, dystonia, ataxia, blurred vision, nystagmus, strabismus, miosis, mydriasis, diplopia, dysarthria, epileptic seizures.

Cardlovascular: Hypotension, dyspnea, palpitation, chest pain, syncope.

Gastrointestinal: Nausea, constipation, dry mouth, anorexia, taste disorder, abdominal pain, vomiting, diarrhea, and positive test for occult blood in stool.

Genitourinary: Urinary frequency, enuresis, urinary retention, dysuria, impotence, inability to ejaculate, nocturia, hematuria.

Other: Rash, pruritus, ankle edema, excessive perspiration, weight gain, nasal congestion. therapy.

Some of the CNS and genitourinary symptoms reported may be related to the underlying disease rather than to drug

The following laboratory tests have been found to be abnormal in a few patients receiving LIORESAL: SGOT, alkaline phosphatase and blood sugar (all elevated).

SYMPTOMS AND TREATMENT OF OVEROOSAGE

Signs and Symptoms: Vomiting, muscular hypotonia, hypotension, drowsiness, accommodation disorders, coma, respiratory depression, and seizures. obtunded patient, secure the airway with a cuffed endotracheal tube before beginning lavage (do not induce emesis).

Maintain adequate respiratory exchange; do not use respiratory stimulants. Muscular hypotonia may involve the respiratory muscles and require assisted respiration. Maintain high urinary output. Dialysis is indicated in severe poisoning associated with renal failure.

\section{DOSAGE AND ADMINISTRATION}

Optimal dosage of LIORESAL requires individual titration. Start therapy at a low dosage and increase gradually until optimum effect is achieved (usually $40-80 \mathrm{mg}$ daily).

The following dosage titration schedule is suggested:

$5 \mathrm{mg}$ t.i.d. for 3 days

$10 \mathrm{mgtid}$ t. for 3 days

$15 \mathrm{mg}$ t.i.d. for 3 days

$20 \mathrm{mg}$ t.i.d. for 3 days

Total daily dose should not exceed a maximum of $20 \mathrm{mg}$ q.i.d.

The lowest dose compatible with an optimal response is recommended. If benefits are not evident after a reasonable trial period, patients should be slowly withdrawn from the drug (see Warnings)

LIORESAL (baclofen) $10 \mathrm{mg}$ tablets: White to off-white flat-faced, oval tablets with GEIGY monogram on one side and the identification code 23 below the monogram. Fully bisected on the reverse side

LORESAL D.S. $20 \mathrm{mg}$ tablet: White to off-white capsule-shaped, biconvex tablets. Engraved GEIGY on one side and GW with bisect on the other.

Available in bottles of 100 tablets.

Product Monograph supplied on request.

References:

1. Cartlidge, N.E.F., Hudgson, P., Weightman, D.: A comparison of baciofen and diazepam in the treatment of spasticity JNeurol Sci. 23: 17-24 (1974)

2. Young, R., Delwaide, P.: Spasticity. New England Journal of Medicine 304: 28-33 \& 96-99 (1981).

3. From, A., Heltberg, A.: A double blind trial with baclofen and diazepam in spasticity due to multiple sclerosis. Acta Neurol. Scandinav. 51: 158-166, (1975)
Co-administration of alcohol, diazepam, tricyclic anti-depressants, etc., may aggravate the symptoms.

Treatment: Treatment is symptomatic. In the alert patient, empty the stomach (induce emesis followed by lavage). In the

\section{AVAILABIUTY}

Prolopa ${ }^{\circ}$

\section{Rx Summary}

Antiparkinsonism Agent

Indications Treatment of Parkinson's syndrome when not drug. induced.

Contraindications Known hypersensitivity to levodopa or benserazide; in patients in whom sympathomimetic amines are contraindicated concomitantly with, or within 2 weeks of MAOI administration; uncompensated cardiovascular, endocrine, renal, hepatic, hematologic or pulmonary disease; narrow-angle glaucoma.

Warnings Discontinue levodopa at least 12 hours before initiating -Prolopa'. See Dosage section for substitution recommendations. Not indicated in intention tremor. Huntington's chorea or druginduced Parkinsonism.

Increase dosage gradually to avoid CNS side effects (involuntary movements). Observe patients for signs of depression with suicidal tendencies or other serious behavioural changes. Caution in patients with history of psychotic disorders or receiving psychotherapeutic agents.

In patients with atrial, nodal or ventricular arrhythmias or history of myocardial intarction initiate treatment cautiously in hospital. Caution in patients with history of melanoma or suspicious undiagnosed skin lesions.

Safety in patients under 18 years has not been established. In women who are or may become pregnant, weigh benefits against possible hazards to mother and fetus. Not recommended for nursing mothers. Precautions Monitor cardiovascular, hepatic, hematopoietic and renal function during extended therapy. Caution in patients with history of convulsive disorders. Upper gastrointestinal hemorrhage possible in patients with a history of peptic ulcer.

Normal activity should be resumed gradually to avoid risk of injury. Monitor intraocular pressure in patients with chronic wide-angle glaucoma. Pupillary dilation and activation of Horner's syndrome have been reported rarely. Exercise caution and monitor blood pressure in patients on antihypertensive medication. 'Prolopa' can be discontinued 12 hours prior to anesthesia. Observe patients on con. comitant psychoactive drugs for unusual reactions.

Adverse Reactions Most common are abnormal involuntary move. ments, usually dose dependent, which necessitate dosage reduction. Other serious reactions are periodic oscillations in pertomance (end aradoxica) atter prolonged therapy. psychiatric disturbances fincluding paranoia, psychosis, depression, dementia, increased libido, euphoria, sedation and stimulation), and cardiovascular effects (including arrhythmias, orthostatic hypotension, hypertension. ECG changes and angina pectoris)

Neurologic, intellectual, gastrointestinal, dermatologic, hematologic. musculoskeletal, respiratory. genitourinary and ophthalmologic reactions have also been reported. Consult Product Monograph for complete list.

Dosage Individualize therapy and titrate in small steps to maxi. mlze benefit without dyskinesias. Do not exceed the recommended dosage range.

Initially, one capsule 'Prolopa' 100.25 once or twice daily, increased carefully by one capsule every third or fourth day (slower in post. encephalitic Parkinsonism) until optimum therapeutic effect obtained without dyskinesias. At upper limits of dosage, increment slowly at 2.4 week intervals. Administer with food.

Optimal dosage is usually 4-8 'Prolopg' 100-25 capsules daily, in 4.6 divided doses.

'Prolopa' 200-50 capsules are intended for maintenance therapy once optimal dosage has been determined using 'Prolopa' $100-25$ capsules. No patient should receive more than $1000-1200 \mathrm{mg}$ levodopa daily during the first year of treatment. 'Prolopa' 50-12.5 capsules should be used when frequent dosing is required to minimize adverse effects.

For patients previously treated with levodopa, allow at least 12 hours to elapse and initiate 'Prolopa' at $15 \%$ of previous levodopa dosage. During maintenance, reduce dosage slowty, it possible. to a maximum of $600 \mathrm{mg}$ levodopa daily.

Supply 'Prolopa' 50-12.5 capsules containing $50 \mathrm{mg}$ levodopa and $12.5 \mathrm{mg}$ benserazide.

'Prolopa' 100-25 capsules containing $100 \mathrm{mg}$ levodopa and $25 \mathrm{mg}$ benserazide.

'Prolopa' 200-50 capsules containing $200 \mathrm{mg}$ levodopa and $50 \mathrm{mg}$ benserazide.

Bottles of 100 .

Product Monograph available on request.

Reterences: 1. Rondot P. Advantages of a Low Dosage of The Levodopa-Benserazide Combination in the Treatment of Parkinson's Disease Med et Hyo 1981:39:3832-3835.2. Data on file. 3 Mondal BK, Mondal KN. Parkinson's Disease in the Elderly: A LongMondal BK, Mondal KN. Parkinson's Disease in the Elderly: A Long
Term Efficacy Study of Levodopa/Benserazide Combination Therapy. Pharmather., 1986:4(9):571-576. 4. Ontario Drug Benefits Plan. December, 1986.

- Registered Trade Mark

(c) Copyright 1987 Hoffmann-La Roche Limited

Hoffmann-La Roche Limited

Etobicoke, Ontario M9C 5J4

PAAB
CCPP

7009

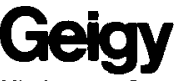




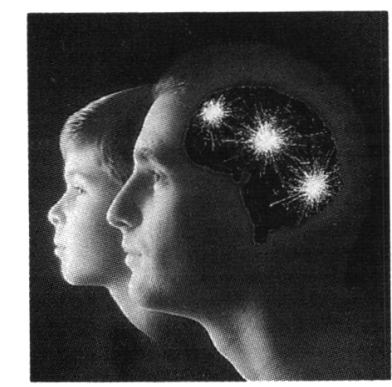

\section{'Depakene' "Epival'}

ACTION Valproic acid and divalproex sodium are chenscally.related antconvutsants. Although their mechanism of action has not yet been establish. ed, it has been suggested that their activity is related to increased brain levels of agmma-aminobutyric acid (GABA). The offect on the neuron membrane is unknown. Epival (divalproex sodium) dissociates into valproic acid in the gastrointestinal tract.

Peak serum levels of valproic acid occur in 3104 hours.

The serum half-life $(t)$ ) of valproic acid is typically in the range of 6 to 16 hours. Half-lives in the lower part of the above range are usually found in patients taking other anti-epileptic drugs. A slight delay in absorption occurs when the drug is administered with meals but this does not aftect the total absorption. Valproic acid is rapidly distributed throughout the body and the drug is strongly bound (90\%) to human plasma proteins Increases in dose may result in decreases in the extent of protein.binding and variable in dose may result in decreases in the extent of protein th

The therapeutic plasma concentration range is believed to be from 50 to $100 \mu$ gimL. Occasional patients may be controlled with serum levels lower or higher than this range A good correlation has not been established between daily dose, serum level and therapeutic effeci.

Elimination of valproic acid and its metabolites occurs principally in the urine, with minor amounts in the feces and expired air. Very little unmetabolized parent drug is excreted in the urine. The principal metabolite formed in the liver is the glucuronide conjugate.

Seo WARNINGS section regarding statement on fatal hepatic dysfunction.

IMDICATIONS AND CLINICAL USE Sole or adjunctive therapy in the treatment of simple or complex absence seizures, including petit mal; usefu in primary generalized seizures with tonic.clonic manifestations. May also be used adjunctively in patients with muttiple seizure types which includ either absence or tonic-clonic seizures.

In accordance with the International Classification of Seizuses, simpte absence is defined as a very brief clouding of the sensorium or loss of con sciousness flasting usually 2.75 seconds) accompanied by certain generalized epileptic discharges without other detectable clinical signs. Complex ed epileptic discharges without other detectable clinical signs.

absence is the term used when other signs are also present.
CONTRAINoICATIOAS Should not be administered to patients with Contralmoications Should not be administered to patients with known hypersensitivity to the drug.

WARMINGS Hepatic failures resutting in fatalities has occurred in patien receiving DEPAKENE* (valproic acid). These incidences usually have occurred during the first six months of treatment with DEPAKENE" (valproic acid). A recent survey study of valproate use in the United States in nearly 400,000 patients between 1978 and 1984 , has shown that children under two years of age who received the drug as part of multiple children under two years of age who received the drug as part of multiple anticonvulsant therapy were at greatest risk (na arly 20.fold increase) of developing fatal hepatotoxicity. These patients typicelly had other medica conditions such as congenital metabolic disorders, mental retardation or organic brain disease, in addition to severe seizure disorders. The risk this age group decreased considerably in patients receiving at somewh monotherapy. Similarly, patients aged 3 to 10 years were al somewhat graater risk if they received muttiple anticonvulsants than those who receiv. ed only valproate. Risk generally declined with increasing age. No death have been

If DEPAKENE* (valproic acid) is to be used in children two years old or younger, it should be used with extreme caution and as a sole agent. The benelits of seizure control should be weighed against the risk. Serious or fatal hepatotoxicity may be preceded by non-specific symptoms such as loss of seizure control, malaise, weakness, lethargy, anorexia, and vomiting. Patients and parents should be instructed to report such symptoms. Because of the non-specific nature of some of the early signs, hepatotoxicity should be suspected in patients who become unwell, other than through obvious cause while taking Epival or Depakene.

Liver function tests should be performed prior to therapy and at frequen intervals thereafter especially during the first 6 months. However, physicians should not rely totally on serum biochemistry since these tests may cians should not rely totally on serum biochemistry since these tests may not be abnormal in all instances, but should also consider the results of be observed in patients with a prior history of hepatic disease. Patients with various unusual congenital disorders, those with severe seizure disorders accompanied by mental retardation, and those with organic brain disease may be at particular risk.

In high.risk patients, it might also be useful to monitor serum fibrinogen and albumin for decrease in concentrations ond serum ammonia for increases in concentration. If changes occur, the drug should be discontinued. Dosage should be titrated to and maintained at the lowest dose tinued. Dosage should be titrated to and

The drug should be discontinued immediately in the presence of signifi cant hepatic dysfunction, suspected os apparent. In some cases, hepatic dysfunction has progressed in spite of discontinuation of the drug. The fre quency of adverse elfects particularly elevated liver enzymes may increase with increasing dose. Therefore, the benefit gained by improved seizure control by increasing the dosage must be weighed against the increased incidence of adverse effects sometimes seen at higher dosages.

Uso in Pregnancy: According to recent reposts in the medical literature valproic acid may produce teratogenicity in the of fspring of women receiving the drug during pregnancy. The incidence of neural tube defects in the etus may be increased in mothers receiving valproic acid during the first trimester of pregnancy. Based upon a single report, it was estimated that the risk of valproic acid exposed women having children with spina bifida is approximately $1.2 \%$. This risk is similar to that which applies to non. epileptic women who have had children with neural tube defects (anencephaly and spina bifidal. Animal studies have demonstrated valproic acid induced teratogenicity and studies in human temales have acid induced teratogenicity, and studies

Mustiple reports in the clinical literature indicate an association between the use of anti-epileptic drugs and an increased incidence of birth defects in children born to epileptic women taking such medication during pregnancy. The incidence of congenital malformations in the general popula. tion is regarded to be approximately $2 \%$; in children of treated epileptic women, this incidence may be increased 2. to 3-fold. The increase is largely due to specific defects, en. congenital malformations of the heart, cleft lip or palate, and neural tube defects. Nevertheless, the great majority of mothers receiving anti-epileptic medications deliver normal infants.

mothers receiving anti-epileptic medic ations deliver normal infanis. Data are more extensive with respect to diphenyllydantoin and phenobar.
bital, but these drugs are atso the most commanly prescribed anti-epileptics. Sorne reports indicate a passible similar association with the use of other enti-epileptic drugs, including trimethadiane, paramethadione, and valproic acid. However, the possibility also exists that other factors, eg. genetic predisposition or the epileptic condition itself may contribute to or may be mainly respensible for the highes incidence of birth defects.

Anti-epileptic drugs should not be discontinued in patients to whom the Anti-epileptic drugs should not be discontinued in patients to whom the possibility of precipitating status epilepticus with attendant hypoxia and risks to both the mother and the unborn child. With regard to drugs given for minor seizures, the risks of discontinuing medication prior to or during pregnancy should be weighed against the risk of congenital defects in the particular case and with the particular family history.

Epileptic women of child-bearing age should be encouraged to seek the counsel of their physician and should report the onset of pregnancy promptly to him. Where the necessity for continued use of anti-epileptic medication is in doubt, appropriate consultation is indicated.

Mursing Mothers: Valproic acid is excreted in breast milk. Concentrations in breast milk have been reparted to be 1 to $10 \%$ of serum concentrations. As a general rule, nursing should not be undertaken while a patien is receiving Epival (divalproex sodium) or Depakena (valproic acid).

Fortility: Chronic toxicity studies in juvenile and adu't rats and dogs demonstrated reduced spermatogenesis and testicular atrophy at doses of valproic acid greater than $200 \mathrm{mg} / \mathrm{kg} / \mathrm{day}$ in rats and $90 \mathrm{mg} / \mathrm{kg} / \mathrm{day}$ in dogs. Segment 1 fertility studies in rats have shown that doses up to $350 \mathrm{mg} / \mathrm{kg}$ iday for 60 days have no effect on fertility. The effect of dival. $350 \mathrm{mg} / \mathrm{kg} / \mathrm{d} a \mathrm{y}$ for 60 days have no effect on fertility. The effect of dival.
proex sodium and valproic acid on the development of the testes and on sperm production and fertility in humans is unknown.

LONG.TERM TOXICITY STUDIES IN RATS AND MICE INDICATEO A POTENTIAL CARCINOGENIC RISK

PRECAUTIOHS: Hepatic dysfunction: Seg CONTRAINDICATIONS and WARNINGS.

General: Because of reports of thrombocytopenia and inhibition of platelet aggregation, platelet counts and bleeding-time determination are recommended before instituting therapy and at periodic intervals. It is reconments surgery. Clinical evidence of hemorrhage bruising or a disorder of hemostasis/caagulation is an indication for reduction of dosage of withdrawal of therapy pending investigation.

Hyperammonemia with or without lethargy of coma has been reported and may be present in the absence of abnormal liver function tests; if eleva. tion accurs the drug should be discontinued.

Because Depakene or Epival may interact with other anti-epileptic drugs, periodic serum level determinations of concurrently administesed antiepileptics are recommended during the early part of thetapy. (See DRUG INTERACTIONS.I There have been reports of breakthrough seizures INTERACTIONS.) There have been reports of breakthrough

Depakene and Epival are partially eliminated in the urine as a ketone. containing metabolite which may lead to a false interpretation of the urine ketone test.

There have been reports of altered thyroid function tests associated with ajproic acid; the clinical significance of these is unknown.

Oriving and Hernndous Occupstions: May produce CNS depression, especially when combined with another CNS depressant, such as alcohol. Therefore, patients should be advised not to engage in hazardous occupa. tions, such as driving a car or operating dangerous machinery, until it is known that they do not become drowsy from the drug.

Orug Interactions: May potentiate the CNS depressant action of Orug
alcohol.

There is evidence that valproic acid may cause an increase in serum phenobarbital levels, by impairment of non-renal clearance. This phenomenon can result in severe CNS depression. The combination of valproic acid and phenobarbital has also been reported to produce CNS depression without significant elevations of barbiturate or valproic acid serum levels. Patients receiving concomitant basbiturate therapy should be closely monitored for neurological toxicity. Serum barbiturate drug levels should be obtained, if possibje, and the barbiturate dosage decreased, it indicated.

Primidone is metebolized into a barbiturate, and therefore, may also be involved in a similar or identical interaction.

There is conflicting evidence regarding the interaction of valproic acid with phenytoin (See PRECAUTIONS - General). It is not known if there is a change in unbound (free) phenytoin serum levels. The dosage of pheny. toin should be adjusted as required by the clinical situation.

The concomitent use of valproic acid and clonazepam may produce bsence status.

Caution is recommended when valproic acid or divalproex sodium is administered with drugs affecting coagulation, eg. acetylsalicylic acid and warfarin (See ADVERSE REACTIONS).

ADVERSE REACTIONS The most commonly reported adverse reactions are nausea, vomiting and indigestion. Since valproic acid has usually been used with other anti-epileptics, it is not possible in most cases to determine whether the adverse reactions mentioned in this section are due to valproic acid alone or to the combination of drugs.

Gastrointestinal: Nausea, vomiting and indigestion are the most com. monly reported side effects at the initiation of therapy. These effects are usually transient and rarely require therapy. Diarrhea, abdaminal cramps and constipation have also been reported. Anorexia with some weight loss and increased appetite with some weight gain have also been seen.
CHS Effects: Sedative effects have been noted in patients receiving alproic acid alone but are found most often in patients on combinatio therapy. Sedation usually disappears upon reduction of other anti-epileptic medication. Ataxia, headache nystagmus, diplopia, asterixis, "spots betore the eves", tremor, dysarthria, dizziness, and incoordination hava rarely been ated. Rare cases of coma have been reported in patients receiving valproic acid alone or in conjunction with phenobarbital.

Dermatologic: Transient increases in hair loss have been observed. Skin rash and petechiae have rarely been noted.

Endocrine: There have been reports of irregular menses and secondery amenorrhea in patients receiving valproic acid.

Abnormal thyroid functian tests have been reported (See PRECAUTIONS)

Psychiatric: Emotional upset, depression, psychosis, aggression, hyper activity and behavioural deterioration have bean reported.

Musculoskaletel: Weakness has been reported.

Hemetopoictie: Thrombocytopenia has been reported. Valproic acid in hibits the second phase of platelet aggregation (See PRECAUTIONS). This may be reflected in altered bleeding time Bruising hematoma formation and frank hemorrhage have been reported. Relative Iymphocytosis and hypofibrinegenemia have been noted. Leukopenia and eosinophilia have also been reported. Anemia and bane marrow suppression have been reported. Hopetic: Minor elevations of transaminases $(00$. SGOT and SGPT) and DH are frequent and appear to be dase related. Occasionally, laboratory tests also show increases in serum bilirubin and abnormal changes in other liver function tests. These results may reflect potentially serious hepatotoxicity (See WARNINGS).

Motabolic: Hyperammonemia (Seo PRECAUTIONS). Hypergtycinemia has been reported and associated with a fatal outcome in a patient with preexisting non-ketotic hyperglycinemia.

Poncrustic: There have been reports of acu

SYMPTOMS AND TREATMENT OF OVERDOSAGE In a reported cose of averdosage with valproic acid after ingesting $36 \mathrm{~g}$ in combination with phenobarbital and phemytoin the patient presented in deep coma. An EEG recorded diffuse slowing, compatible with the state of consciousness. The patient made an uneventful recovery.

Naloxone has been reported to reverse the CNS-depressant effects of valproic acid overdosage.

Because naloxone could theoretically also reverse the anti-epileptic efrects of Depakene or Epival, it should be used with caution.

Since Epival tablets are enteric.coated, the benefit of gastric lavage or emesis will vary with the time since ingestion. General supportive measures should be applied with particular attention to the prevention of hypovolemia and the maintenance of adequate urinary output.

DOSAGE AND ADMINISTRATION The recommended initial dosage is $15 \mathrm{mg} / \mathrm{kg} / \mathrm{day}$, increasing at one week intervals by 5 to $10 \mathrm{mg} / \mathrm{kg} / \mathrm{d}$ ay until seizures are controlled or side effects preclude further increases.

The maximal recommended dosage is $60 \mathrm{mg} / \mathrm{kg} / \mathrm{day}$. When the total daily dose exceeds $125 \mathrm{mg}$, it should be given in a divided regimen (See Table)

The frequency of adverse effects (particularly elevated liver enzymes) may increase with increasing dose. Therefore the benefit gained by improv. ing seizure contral must be weighed sgainst the increased incidence of adverse effects.

As the dosage is raised, blood levels of phenobarbital or phenytoin may be affected (See PRECAUTIONS)

Patients who experience G.l. irritation may benefit from administration of the drug with food or by a progressive increese of the dose from an initia low level. The capsules or tablets should be swallowed without chowing.

AVAILABILITY Depakene \{valproic acid\} is avalable as orange coloured soft gelatin capsules of $250 \mathrm{mg}$ in bottles of 100 capsules; pale yellow, oval, soft gelatin enteric-coated capsules of $500 \mathrm{mg}$ in bottles of 100 cap. sules: and as a red syrup contzining the equivalent of $250 \mathrm{mg}$ valpsoic acid. as the sodium salt, per $5 \mathrm{~mL}$ in bottles of $450 \mathrm{~mL}$.

Epival (divalproex sodium) enteric-coated teblets are available as salmon. pink coloured tablets of $125 \mathrm{mg}$; peach-coloured tablets of $250 \mathrm{mg}$ lavender-coloured tablets of $500 \mathrm{mg}$. Supplied in bottles of 100 tablets. Toble of Initial Doses by Weight (based on $15 \mathrm{mg} / \mathrm{kg} / \mathrm{day}$ )

\begin{tabular}{|c|c|c|c|c|c|}
\hline \multirow[b]{2}{*}{$\mathrm{kg}$} & \multirow[b]{2}{*}{ lb } & \multirow{2}{*}{$\begin{array}{l}\text { Total doily } \\
\text { dose (mg) }\end{array}$} & \multicolumn{3}{|c|}{ Dosage } \\
\hline & & & Dose 1 & Dose 2 & Dose 3 \\
\hline 10.24 .9 & 22.54 .9 & 250 & 125 & 0 & 125 \\
\hline 25.39 .9 & 55.87 .9 & 500 & 250 & 0 & 250 \\
\hline 40.59 .9 & 88.131 .9 & 750 & 250 & 250 & 250 \\
\hline 60.74 .9 & 132.164 .9 & 1,000 & 250 & 250 & 500 \\
\hline 75.89 .9 & 165.197 .9 & 1,250 & 500 & 250 & 500 \\
\hline
\end{tabular}

Product monograph available on request.

Henriksen O, Johannessen SI. Clinical and pharmacokinetic observations on sodium valproate - A 5.year follow.up study in 100 children with epilepsy. Acta Neurol Scand 1982;65:504-523.

2. Delgado-Escueta AV et al. The Treatab!e Epilepsies. New Engl J Med 1983;308(26):1576.1584.

3. Turntull OM et at. A comparison of phenytoin and valproate in previously untreated

4. Chadwick DW Valproate Monotherapy in the Mananement of Generalized and Partial Seizures. Epilepsia 1987;28(2):S12-S17.

5. Wilder BJ at al. Gastrointestinal tolerance of divalproex sodium. Neurology 1983;33(6):808-811.

6. Loiseau $P$. Rational Use of Valproate: Indications and Drug Regimen in Epilepsy. Epilepsia 1984:25(1):S65.S72.

7. American Academy of Pediatrics Committee on Drugs. Behavioural and Cognitive Effects of Anticanvelsant Therapy. Pediatrics 1985; 76i4\}:644-647.

8. Beghi E et al. Adverse Reactions to Antiepileptic Drugs: A Multicenter Survey of Clinical Practice. Epilepsia 1986;27(4):323-330.

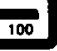

PHARMACEUTICAL PRODUCTS DIVISION ABEOTT LABORATORIES, LIMITED MONTAEAL, CANADA

PAbbott Leboratories. Limited PMAB see pages viii, ix 
DSYMMETREL ${ }^{(1}$ (Amantadine HC) Antiparkinsonian Agent INAICATIONS: The treatment of Parkinson's syndrome and in the short-term managgement of drug-induced extrapyramidal symptoms.

CONTRAMDICATIONS: Patients with krown hypersensitivity to the drug. WARNINGS:Patient w with a history of epplessy or other "seizures" should be observed closely for possible untoward central nenvous system eftects. Patients with a history of congessive heart tialure or peripheral etema should be followed closely as there are patients who developed congestive heart tailure while receiving SYMMETRE: Sately of use in pregnancy has not been established. SYMMETREL should not be used in women of childbearing potential, unless the expected benefit to the patient outweighs the possible risk to the fetus.

SYMMETREL" is secreted in the milk and should not be administered to nursing mothers.

PRECAUTIOHS: The dose may need careful adjustment in patients with renal impairment congestive heart faiture, perioheral edema or orthostatic hypotension. Since SYMMETREL" is not metabolized and is mainly excreted in the urine, it may accumulate when renal function is inadequate.

Care shoudd be exercised when administering to pationtis with fiver disease, a history of recurrent eczemataid rash, Dsychosis, or severe psychoneurosis not controlled by chemotherapeutic agents. Caretul obsevation is reauried when administered concurrently with central nevous system stimulants.

Patients with Parkinson's syndrome improving on SYMMERREL" should resume normal activities gradually and cautiously, consistent with other medical considera. tions. such as the presence of osteoporosis or phebothrombosis. Patients receiving SYMMETREL' who note central nervous system effects or bluring of vision should be cautioned against driving or working in situations where aetrness is important. SYMMETRELE should not be discontinued abruptly since a tew oatients with Parkin. son's synorome experienced a parkinsonian crisis, ie., sulden marked clinica deterioration, when this medication was suldenly stopped.

The dose of antichoinergic drugs or of SYMMETREI should be reduced fif atropine-like eftects appear when these drugs are used concurrently.

ADVERSE REACTIONS: Adverse reactions have occured in patients while receiving SYMMEREEE alone orin combination with anticholinergic antiparkinison drugs and/or levodopa.

Important adverse reactions are orthostatic hypotensive episodes, congestive heart tailure, depression, asychosis and urinary retention; and rarely convulsions, rever. sible leukopenia and neutropenia, and abnormal liver function test results.

Atverse reactions of less importance are: anocexia, anxiety, ataxia, confusion. hallucinations, constipation, diziness (light-headedness), dry mouth, headache insomnia, livedo reticularis nausea, perioheral edema drowsness, duspnea, fatioue hyperkinesia, irritability, nightmares, rash, slurred speech, visual disturbance, vomiting and weakness; and very rarely eczematoid dermatitis and oculogyric episodes. Some side effects were transient and disappeared even with continued administration of the drug.

SYMPTOMS ANO TREATMENT OF OVEROOSAGE: Limited data are avaliabte concerning clinical effects and managenent of SYMMETREE overdos sage. An edderly patient with Parkinson's syndrome who took an overdose of $2.8 \mathrm{~g}$ of SYMMETREL ${ }^{3}$ in a sucicida attempt, developed acute toxic psychosis, vinary retention, and a mixed acid-base disturbance. The toxic nsychosis was manifested bydisorientation. confusion, visual hallucinations and aggressive behaviour. Convulsions did not occur, possibly because the patient had been receiving phenyton prior to the acute ingestion of SYMMETREL?

There is no specilic antidote. For acute overdosing, general supportive measures should be enployed, along with immediate gastric lavage or induction of emesis. Fluids should be forced, and if necessary, giver. IV. The ph of the urine has been reported to influence the exccetion rate of SYMMETRELE? Since the excretion rate of SYMMETREE" increases rapidly when the urine is acidic, the administration of urine acidifing fluds may increase the elimination of the drug from the body Blood pressure, pulse, respiration and temperature should be monitored. The patient should be observed for possible development of arrhythmias. hypotension, hyperactivity, and convulsions, if required, approporate therapy shours be administered. Blood elec. trolytes, urine ph and uriary output should be monithored. It there is no recosd of recent voiding, catheterization should be done. The possibility of multiple drug ingestion by the patient should be considered.

DOSAGE AND ADMINISTRATION: Parkinson's Syndrome: Initial dose is $100 \mathrm{mg}$ daly for patients with serious associaled medical illnesses or who are recevining high doses of ther antiparkinson drugas. After one to several weeks at $100 \mathrm{mg}$ once daily. the dose may be increased to $100 \mathrm{mg}$ twice dalily. When SYMMETRE[ and levodopa are initiated concurrently. SYMMETREL" should be held constant at $100 \mathrm{mg}$ daly or twice dalily while the daily dose of levododo is gradually increased to optimal dose. When used alone, the usual dose of SYMMETREE" is $100 \mathrm{mg}$ twice a day.

Patients whose responses are not optimal with SYMMETREE at 200 mg daily may benefit from an increase to $300 \mathrm{mg}$ dalily in divided doses. Patients who experience a fall -of of feftectiveness may regain berefit by increasing the dose to $300 \mathrm{mg}$ dally: such patients should be supervised closely by their physicians.

DOSAGE FORMS: Capsules: (bottles of 100) - each red, sott geiatin capsule contains $100 \mathrm{mg}$ of amantadine HCI. Syrup: (500 $\mathrm{mL}$ ) - each $5 \mathrm{~mL}$ (1 teaspoonfiul) of clear colorless syrup contains $50 \mathrm{mg}$ of amantadine $\mathrm{HCl}$.

\section{Rederences:}

1. Schwab RS, Poskanzer OC, England AC Jr., Young RR: Amaritacine in Pakkinson's disease. JAMA 1972;227:7.

Product monograph available on request.

'PAAB' (ㄱ)

Du Pont Pharmaceuticals

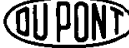

Mississauga, Ontario L5M 2J4

\section{It only takes a moment to show how much you care.}

Precious moments. To help a grandchild learn. To share something of your day your knowledge, your love and care. Moments that add up to being remembered, forever.

It only takes a moment, too, to help make the world of your grandchildren a safer, happier place. By leaving a sum of money to the Canadian Cancer Society in your Will. The addition of a simple sentence, "I give to the Canadian Cancer Society, the sum of dollars," will add up to real and measurable assistance to ongoing cancer research programmes.

Great strides are being made in the fight against cancer. And will continue to be made. If you'll just take that precious moment to remember the Canadian Cancer Society in your Will.

That, too, will be a moment for which you'll be remembered forever.

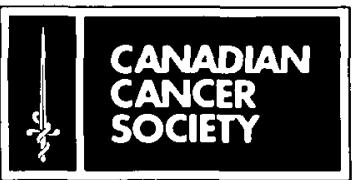

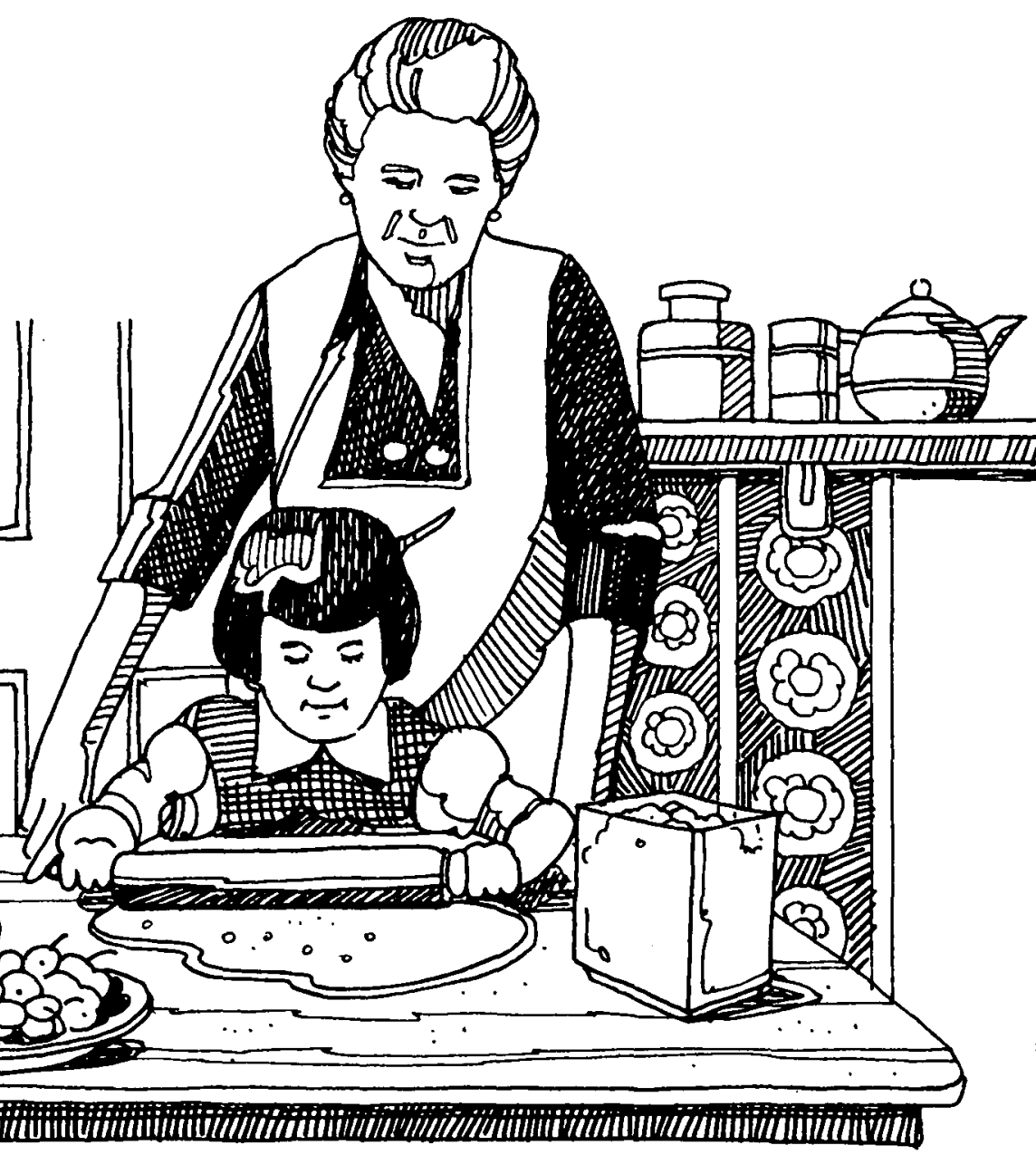

see page xix 


\section{Neurosurgery clinical and research fellow}

Fulltime position available for 1 year beginning July 1989 for clinical and research experience in neurosurgery. The special fields of interest which are available include spinal injuries, posterior fossa tumors, neuro-oncology and cerebrovascular disease.

Candidates must already have completed a neurosurgical training program.

Reply with curriculum vitae and name of two referees to:

\section{C.H. Tator, M.D.}

Division of Neurosurgery and Playfair

Neuroscience Unit,

Toronto Western Hospital,

399 Bathurst St., Suite 2-003 ECW

Toronto, Ontario

M5T $2 S 8$
Academic neurologist with sub-specialty training in neuro-ophthalmology wanted for fulltime faculty position in the Toronto Western Division of The Toronto Hospital and the University of Toronto. Responsibilities include service on the neurology and medical wards, and a neuro-ophthalmology clinic as well as medical student and resident teaching. The applicant should be eligible for certification by the Royal College of Physicians, Canada. In accordance with Canadian immigration requirements, priority will be given to Canadian citizens and permanent residents. Please send curriculum vitae, and letters of references to:

\section{Dr. James A. Sharpe}

Head, Division of Neurology

Toronto Western Hospital

399 Bathurst St.

Toronto, Ontario

M5T $2 S 8$
ACADEMIC ADULT NEUROLOGIST:

Full time appointment available in Division of Neurology, Department of Medicine, University of Saskatchewan. Demonstrated capabilities in teaching and research, with special interest in EEG and epilepsy is desirable. Applicant must have a fully unrestricted license to practise medicine in Canada. In accordance with Canadian Immigration requirements, priority will be given to citizens and permanent residents of Canada. Forward CV with names of three referees to:

DR. R.M. BALA, CHAIRMAN

DEPARTMENT OF MEDICINE UNIVERSITY OF SASKATCHEWAN SASKATOON, CANADA S7N OXO

\section{ADVERTISER'S INDEX}

Abbott

Epival - viii, ix, xxiii

Cordis Canada - xvii

Ciba/Geigy

Lioresal - iv, xxii

Tegretol - obc, xii, xxi

Dantec Electronics Ltd.

Concerto - ii

Counterpoint - xviii

Neuroscope - $x v$

Dupont

Symmetrel - xix, xxiv

Hoffman La Roche - xvi, xxii

Nicolet Instruments - vi, vii

Nihon Kohden - xi, xiii

Parke Davis Canada Inc.

Dilantin - ibc, $x x$

Sandoz Canada Inc.

Parlodel - ifc, i, xiv

Classified Ads - xxv, xxvi 


\section{CHAIRMAN \\ DEPARTMENT OF CLINICAL NEUROLOGICAL SCIENCES THE UNIVERSITY OF WESTERN ONTARIO}

Applications are invited for the position of Chairman of the Department of Clinical Neurological Sciences, The University of Western Ontario, London, Ontario, Canada. The Department, actively involved in education, research and clinical practice, consists of 28 full-time faculty members and 21 part-time members working in three major affiliated teaching hospitals. The Department consists of two Divisions, neurosurgery and neurology, and has a large commitment to clinical and basic investigation.

The position requires an individual with strong leadership and administrative skills, a commitment to academic excellence and a distinguished record of research and teaching.

Applications should be sent by February 28,1989 , to:

\section{Dr. L.S. Valberg, Dean}

Faculty of Medicine

The University of Western Ontario

London, Ontario, Canada N6A 5C1

Positions are subject to budget approval. In accordance with Canadian Immigration requirements, this ad is directed to Canadian Citizens and Permanent Residents of Canada. The University of Western Ontario is an Equal Opportunity Employer.
The Division of Neurology at the University of Toronto wishes to recruit a full-time faculty member to an appointment at the Toronto General Hospital. A major responsibility will be the direction of the Clinical Neurophysiology Laboratory which provides EEG and evoked potential studies and associated academic programs. The Toronto General Hospital is a division of the Toronto Hospital Corporation with special interests in cerebrovascular, neurodegenerative and neuromuscular diseases and is closely integrated into the programs of the University of Toronto teaching hospitals that include most of the subspecialties in neurology. The appointee will have responsibilities for teaching and clinical or laboratory research and patient care appropriate to the academic responsibilities. Candidates must have certification by the Royal College of Physicians and Surgeons of Canada or its equivalent. In accordance with Canadian immigration regulations, Canadian citizens and landed immigrants must be considered before offers can be made to non-Canadians. Interested applicants should send a curriculum vitae to:

$$
\begin{gathered}
\text { Dr. John R. Wherrett } \\
\text { Division of Neurology } \\
\text { Room } 221-11 \mathrm{EN} \\
\text { Toronto General Hospital } \\
200 \text { Elizabeth St. } \\
\text { Toronto, Ontario M5G } 2 \mathrm{C} 4
\end{gathered}
$$

\section{ALS IN THE NAVY}

The Departments of Veterans Affairs and National Defense have funded a study on the possible association between work in the navy and the subsequent development of amyotrophic lateral sclerosis.

The study requires a nationwide sample of all ALS patients, living and deceased, diagnosed between (and including) the years of 1950 and 1988.

The study team greatly appreciates support from all neurologists in providing the names, ages and addresses of all such patients.

Information should be sent to:

\section{Dr. R. Marchant}

Associate Professor of Occupational and

Environmental Medicine

Dalhousie University

5849 University Ave.

Halifax, N.S. B3H $4 \mathrm{H} 7$

\section{EASTERN STATE HOSPITAL}

Eastern State Hospital is a 392 bed J.C.A.H.O. accredited facility serving Eastern Washington.

Currently, the hospital has psychiatric vacancies in its forensic, geriatric and adult psychiatric programs.

Applicants should have an excellent knowledge of psychopharmocology, the ability to be comfortable working in an interdisciplinary setting and relate well to mental health centers and the community.

Benefits are excellent, including vacation, holidays, sick leave, life insurance, medical/dental insurance and generous administrative leave for continuing medical education. Salary: $\$ 85,740$ plus additional compensation for on call duty.

The hospital is situated 20 minues from Spokane in the heart of the Pacific Northwest. Spokane offers a wide range of cultural and educational opportunities including symphony, civic theater, two four year colleges, two community colleges, and Eastern Washington University.

Nearby mountains and lakes, within less than an hour's drive, offer excellent skiing, fishing, sailing and hunting. Several public as well as private golfing facilities are in the immediate vacinity.

In addition, the cost of living and price of housing are below the national average.

Interested psychiatrists should contact Mr. Laurie Zapf, collect (509) $299-4351$ or P.O. Box A, Medical Lake, WA 99022, for further information. 


\section{ANOTHER UNEVENTFUL DAY.}

\section{DILANTIN \\ (phenytoin)}

Start with it. Stay with it.

DILANTIN* (phenytoin) is a drug of first choice for controlling generalized tonic clonic seizures.

No other antiepileptic is more widely prescribed.

No other antiepileptic has been the subject of more extensive clinical studies?
And no other antiepileptic boasts a more simplified medication schedule. The slow absorption of Dilantin Capsules allows a single daily dose for maintenance therapy in many adults, once the divided dose of three $100 \mathrm{mg}$ capsules has adequately controlled seizures.

\section{PARKE-DAYIS}




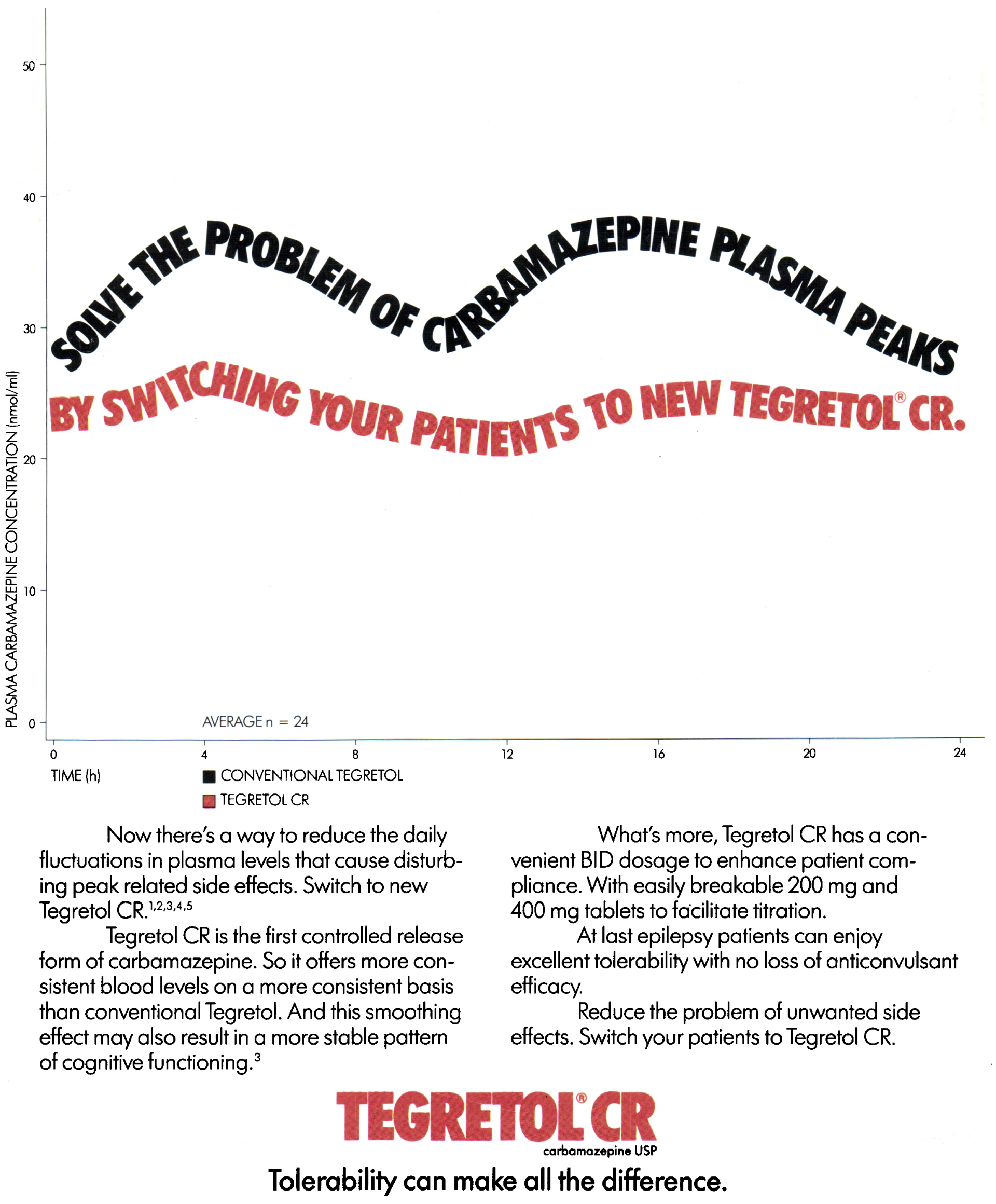

